\title{
Digitizing Patterns of Power - Cartographic Communication for Digital Humanities
}

\author{
Karel Kriz, ${ }^{\mathrm{a}}$ Alexander Pucher, ${ }^{\mathrm{a}}$ Markus Breier, ${ }^{\mathrm{a}}$ \\ ${ }^{a}$ University of Vienna, Department of Geography and Regional Research,Vienna, Austria; karel.kriz@univie.ac.at, \\ alexander.pucher@univie.ac.at, markus.breier@univie.ac.at
}

\begin{abstract}
The representation of space in medieval texts, the appropriation of land and the subsequent installation of new structures of power are central research topics of the project "Digitizing Patterns of Power" (DPP). The project focuses on three regional case studies: the Eastern Alps and the Morava-Thaya region, the historical region of Macedonia, and historical Southern Armenia. DPP is a multidisciplinary project, conducted by the Austrian Academy of Sciences the Institute for Medieval Research (IMAFO) in cooperation with the University of Vienna, Department of Geography and Regional Research. It is part of an initiative to promote digital humanities research in Austria. DPP brings together expertise from historical and archaeological research as well as cartography and geocommunication to explore medieval geographies. The communication of space, time and spatial interconnectivity is an essential aspect of DPP. By incorporating digital cartographic expertise, relevant facts can be depicted in a more effective visual form. Optimal cartographic visualization of base data as well as the historical and archaeological information in an interactive map-based online platform are important features. However, the multidisciplinary of the project presents the participants with various challenges. The different involved disciplines, among them cartography, archaeology and history each have their own approaches to relevant aspects of geography and geocommunication. This paper treats geocommunication characteristics and approaches to interactive mapping in a historical and archaeological context within a multidisciplinary project environment. The fundamental challenges of cartographic communication within DPP will be presented. Furthermore, recent results on the communication of historical topographic, as well as uncertain thematic content will be demonstrated.
\end{abstract}

Keywords: Cartographic Communication, Topographic Maps, Cartographic Visualization, Spatial Uncertainty, Digital Humanities, Multidisciplinary

\section{Introduction}

The perception, depiction and organization of spaces and places in the Middle Ages encompass an interdisciplinary research field which helps to understand historical processes and relations within the medieval period. The representation of space in medieval texts, the appropriation of land and the subsequent installation of new power-structures are central research topics of the project "Digitizing Patterns of Power" (DPP).

These patterns of power, established in space and time, are the research focus of this interdisciplinary project. The research questions are the domain of historical scholarship, but the phenomena are to a large extent spatial phenomena. The representation and analyses of spatial phenomena are core competences of cartography and geographical information science.

DPP is a multidisciplinary project, conducted by the Austrian Academy of Sciences the Institute for Medieval Research (IMAFO) in cooperation with the University of Vienna, Department of Geography and Regional Research. (IfGR). It is part of the program "Digital Humanities: long term projects on cultural heritage". This program is an initiative of the Austrian Academy of Sciences to promote digital humanities research in Austria. It started in January
2015 and will end in Dezember 2018. The aim of DPP is the development a generalizable workflow from the digitization of a specific corpus of textual and archaeological evidence to the analysis and visualization of data with the help of digital tools.

Cartography and geocommunication are vital parts in the representation and visualization of the historical landscape and the underlying data. (Bodenhamer et al. 2010, Gregory \& Ell 2007) The creation of project specific base maps from free geodata, the visualization of the uncertainty inherent in historical data and the development of methods of interactive geocommunication to create a sustainable online presentation of data and results of the research is central for DPP.

\section{Case Studies and historical research questions}

The project will focus on four case study regions. Historical research questions come from these case study regions.

- The Carolingian eastern Alps (8th /9th century)

- The March/Morava - Thaya/Dyje border region (7th -11 th century)

- The historical region of Macedonia (12th - 14th century) 
- Historical southern Armenia: the rise and fall of Vaspurakan (5th -11 th century)

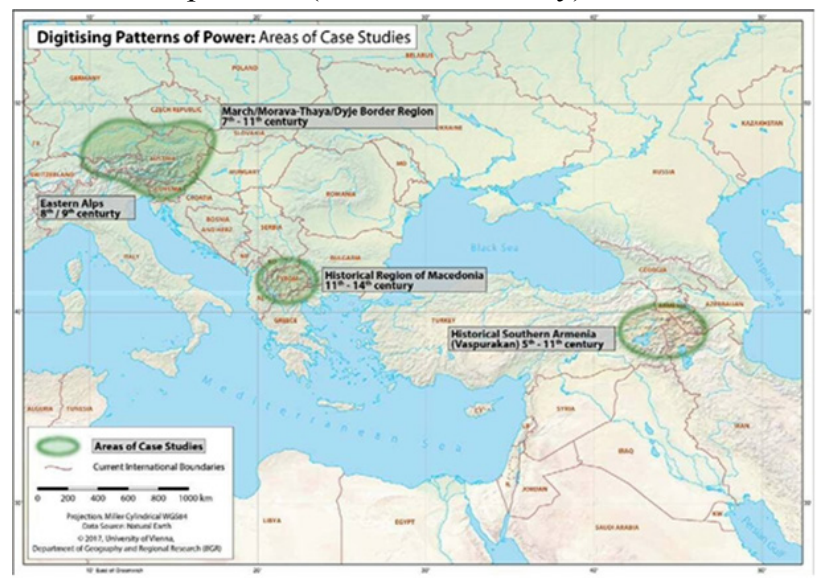

Fig. 1. The case studies of DPP

Although located in different parts of Europe and Asia Minor as well as being in different timeframes, these regions share a common basis of mountainous ecologies ${ }^{1}$, their position on the peripheries of imperial spheres and the specific framework provided by these conditions for the emergence and dynamics of political and socioeconomic structures.

One research topic is the appropriation of space through creating "places of power" and possible underlying strategies. Is there a correlation between the increase in density of sites - e.g. settlements, fortifications, churches and monasteries, market places etc. - and an intensifying need for control over the land and its gradual appropriation? Another issue is the interplay between built and natural environment.

In the eastern Alps and its surroundings, different structures were established in the late Roman Empire, the Carolingian expansion in the 8th and 9th century and the medieval internal colonization of the Eastern Alps region starting from the 10th century. Ecclesial institutions vied for influence to control the trade and pilgrimage routes to the south. (Winckler 2012)

The Morava/Thaya region is and has always been a border region not only today, but also during the medieval age. The political and social entities on both sides of the border have left certain patterns of power in the landscape. Due to the lack of historical sources in this case study the focus will be on archaeological sources. (Eichert 2012)

At the territory of today's Former Yugoslavian Republic of Macedonia (FYROM), research is conducted on the transformation of the region from a Byzantine province into an area of military and political expansion by the Serbian medieval empire. Impacts on settlement patterns, re-distribution of landed property, interplay between resident popu- lation and nomads (Popović 2014/2015)

${ }^{1}$ The Morava/Thaya region is not a mountainous region, but it serves as comparison to the other areas of research in order to elaborate on terrain specific or terrain independent developments. and the establishment of new infrastructure are of interest.

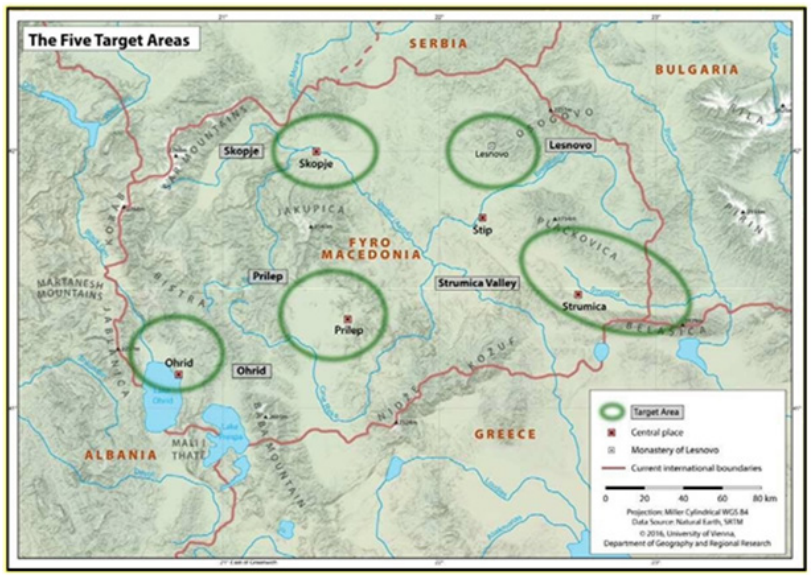

Fig. 2. Target areas within the case study Macedonia

In the historical region of southern Armenia, research focuses on the region around Lake Van and on the emergence of the principality of the noble house of Arcruni in the period between the end of the ancient Armenian monarchy

(428) and the Seljuk conquest of Armenia (1020-1070). Textual evidence as well as archaeological data provides further input for a comprehensive analysis and visualization of the construction of an early medieval polity both in the narrative and in space within the specific ecology of the Van region at the crossroads between Byzantium and the Islamic World. (PreiserKapeller 2010/2012)

The project builds on information and data gathered by the project partners from the Academy of Sciences. Data from various previous projects is incorporated, but also new data is acquired for DPP. The data gathered for DPP comprises of archaeological and historical sources. Archaeological entities include artefacts, monuments, settlements and burial sites Historical information is extracted from written sources like charters, chronicles and travel reports. This information is geotagged and entered in a common database.

\section{Base Maps}

To provide a background for the historical information, a specific base map has to be created, which suits the needs of the historians and archaeologists. This is a critical task, since ideally, the map should represent the landscape at the timeframe appropriate for the research question. However, there are some difficulties to this undertaking. For one, it is very difficult to near impossible to get geodata of the medieval landscape. Not only man-made features like settlements and land use have changed, but also natural features like the course of rivers, coastlines and the extent of lakes have changed during history. Although there has been research on historical courses of some rivers, there is no comprehensive and consistent data available for all relevant regions. Furthermore, the project spans a timeframe of nine centuries, from the 5 th to the 14th century. This is a huge timespan, with the 
earliest nearly as far from the latest as the latest from present day. In a time before river regulations, the courses of the rivers would have changed a lot over a timespan of nine centuries. Overall, it was decided that the base map of DPP is based on current geodata, which will serve as a viable approximation.

Another point of discussion with historians was the inclusion of current international borders and cities in the base map. From a cartographic point of view, they serve as means of orientation, since most map users are familiar with the rough shape of the countries and the location of the major cities. It provides a frame of reference, to refer from the map to the real world. For medievalist on the other hand, as was evident in personal discussions, these features are a distraction, since they did not have any meaning during the Middle Ages. It was argued, that these features are not only a distraction, but that current international borders would promote a nation-centric historiography, which is hard to overcome for students of history or the general public.

For DPP therefore, two base maps will be available. The default base map is without current borders and cities, focusing on relief, waterbodies and land use. An alternative version is available, which includes the international borders, important cities and the according labels.

Both base maps are created from free geodata, using GTOPO 30, Natural Earth waterbodies and UMD global land cover data for the lower zoom levels (5 - 7), SRTM, OSM and Hansen global forest data for the higher zoom levels (8-11).

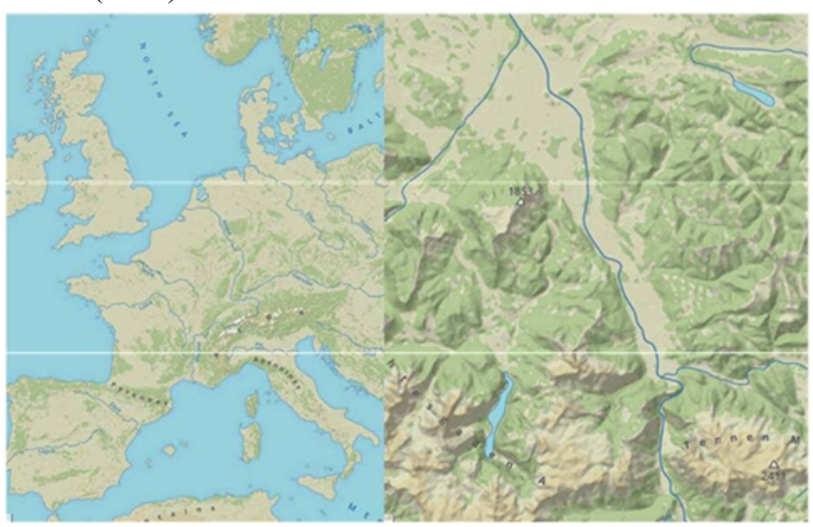

Fig. 3. Base map without modern features. Zoom level 5 (left) and zoom level 11 (right)

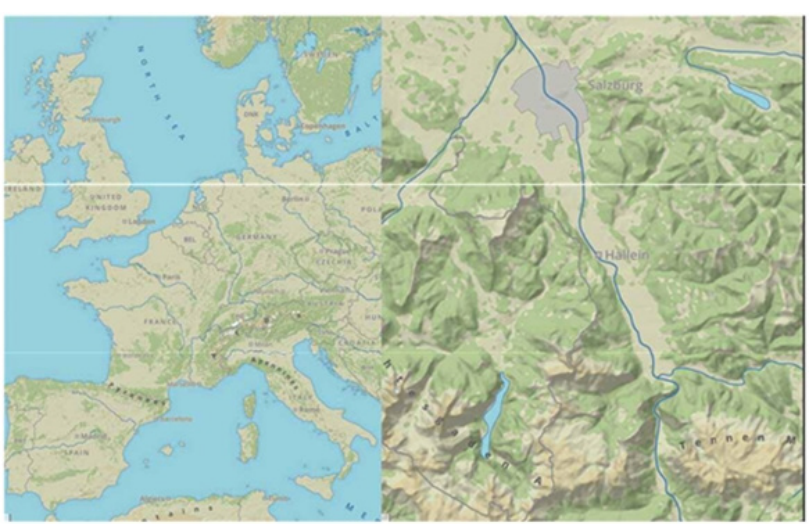

Fig. 4. Base map with modern features. Zoom level 5 (left) and zoom level 11 (right)

\section{Spatial Uncertainty of Historical data}

DPP builds on various historical data. This includes data from archaeological excavations, data extracted from historical written sources and secondary data from other sources, like old maps.

Due to the nature of the data sources, the data quality especially the accuracy and certainty - varies greatly. This is true for the spatial as well as the temporal aspect. Data gathered during archaeological surveys are very precise in the spatial aspect - it is recorded with surveying techniques or at least GPS. The precision of temporal aspects varies, depending on the applicable method of dating.

On the other hand, data extracted from written sources is much more imprecise and uncertain. (Jänicke \& Wrisley 2013) The references in the written sources are often very vague, e.g. a location was in the vicinity of a town, or situated within an administrative unit or nearby a geographical feature.

This is further complicated by the fact that the entity, which the location is referenced to, can be located only vaguely itself. The exact extent of historical administrative units or the area of influence is very hard to determine. Such historical entities were often not clearly defined even during the time they existed. It is one of the aims of this project, to use the available data to reconstruct these areas.

Toponyms often change, and even if the names stay (more or less) the same, the location or extent of the entities change. Settlements grow or shrink over time, and sometimes change location. An example would be a village that is situated in a river valley which is then destroyed by a flood. It could be rebuilt a little further up the slope of the valley. The name would be retained, but the location has changed. In some cases, the written sources contain references to places, with two or more possible locations, i.e. the written source gives the name of the village with no additional information, and there are two villages with the same name. It is therefore unclear, to which of the two source it refers to.

All these uncertainties make it difficult to give exact coordinates to the events and locations. The historical research questions of DPP, however, make it necessary to record the level of uncertainty of the data in the database. Further- more, the uncertainty will be represented scale dependent in the map based application. Approximation methods, like assigning the data to the center of the current administrative unit or guessing where the location was most likely, are not desirable for this project.

How to best handle uncertainty in such an environment is one of the main cartographic research questions of this project. Although various approaches to uncertainty visualization exist (e.g. MacEachren 2005, Reuschel \& Hurni 2011), these approaches have to be adapted for the use in an interactive application with many different data entities. 


\section{Geocommunication}

The map based application serves as a tool for research itself. By enabling the user to combine various datasets and results of database queries, spatial relations can be explored.

However, it is not the aim of DPP to create a full-fledged WebGIS. DPP focuses on optimal representation of the data and its uncertainty as well as on usability especially for non-GIS experts and performance (Kriz 2013). The application should guide the user through the data, allowing to query the database and show various data layers over a purpose made base map.

The prototype of the application, which was finished in February 2017, offers a basic query interface for the database and navigation. The available zoom levels are from 5 to 11 . The aim is to provide base maps for the whole extent of the case studies up to zoom level 13. For selected hotspots, even higher zoom levels are considered. Data entities are displayed as dots and are clustered, because there are areas with very high data density. Polygon and uncertainty representation is not yet available in the prototype, but will be an important feature for the final application. The links between various data entities like places, events, actors and signs of power can be followed via hyperlinks, which allows to explore the spatial relations between the entities.

The final application will also offer a full text search. The functionality will include the possibility to query the database via text based input as well as interacting with the map. It will be possible to use the results as a starting point for browsing the data, switching between the map view and the database view.

The map view will provide spatial aspects and selected thematic information of the data, whereas the database view will provide access to the full information and relations to other data entities. A time slider allows the user to gain insight to the temporal aspects.

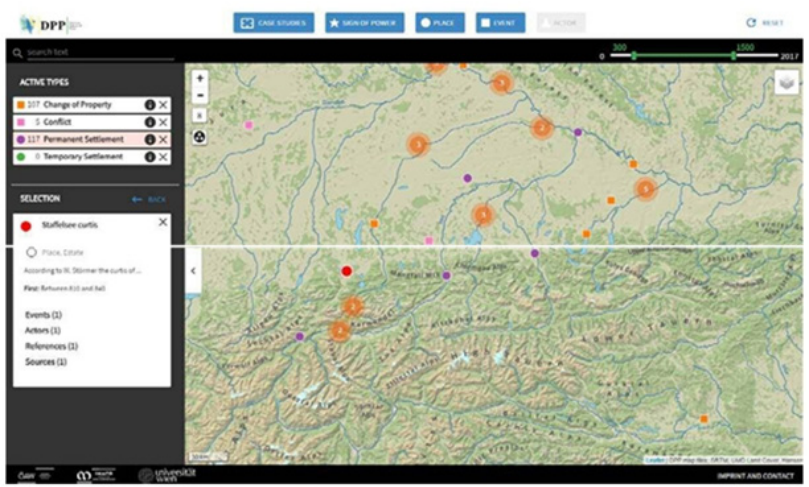

Fig. 5. Prototype of interactive application

With these tools, the data can be explored in its spatial, temporal and thematic aspects to help in answering the historical research question.

Cartographic applications are not only used as a research tool in DPP. The map based application will also serve as a platform for communicating the results of DPP to a wider audience. To keep the application accessible, ease of use and a clearly structured functionality is a key requirement for the application. However, the application should not be simplistic, because of the complex thematic content.

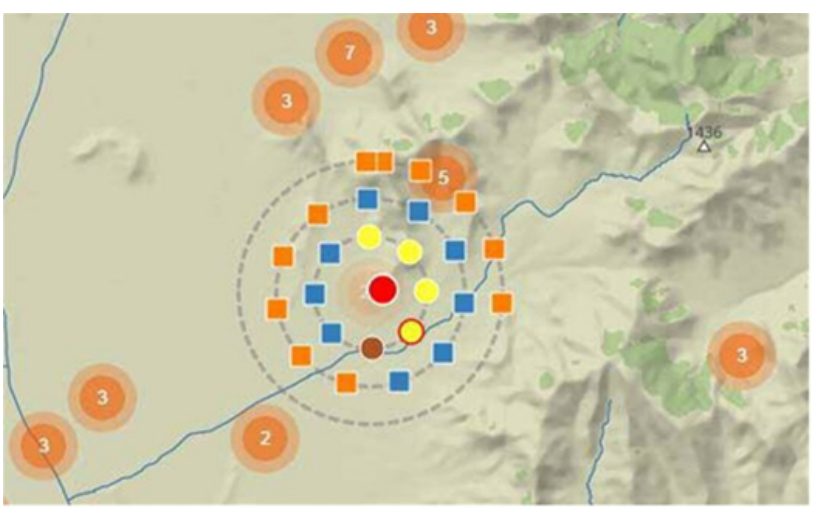

Fig. 6. Clustering in the DPP application

To communicate key results of the project to the public, so called "Story Maps" will be included in the application. These "Story Maps" are predefined views of the data, consisting of database queries, which are complemented with a detailed description of the topic shown and information about its significance for the historiography.

\section{Data structure}

The database system is the technical backbone of the project DPP. "OpenATLAS", an object-oriented database system established during previous research at the Institute for Medieval Research is used to create a common data pool. It joins data from archaeological as well as historical sources and uses classes and properties from the CIDOC Conceptual Reference Model (CIDOCCRM, Le Boeuf at al. 2015). Originally created with cultural heritage management in mind, it is update to meet the criteria for DPP. It can map historical and archaeological entities like sites, features, stratigraphic units and finds, documents, events and actors - which can be persons or institutions. Further- more, the relations between these entities and spatial and temporal information are modelled. Metadata, connections to bibliographical resources, image data, textual content, online resources, administrative units and record restrictions like copyright or licensing of various datasets can be recorded. The database is connected to the interactive map based online application via PHP based server code. The application itself is programmed in Java Script, making use of the Leaflet library. Communication between server sided database access and client side application is handled by GeoJSON (Java Script Object Notation).

However, its object-oriented structure, complex data relations and dynamic elements make it challenging when visualizing the entities and their relations in an interactive application.

According to the OpenData policies of the involved institutions, the data collected during the project will be provided to the public. Geodata will be accessible via Web Feature Service (WFS). In this way, expert users can 
use the data within their own GIS and conduct analyses and queries, which are not possible in the online application. The software developed for this project is based on Open Source components and will be available to similar projects.

\section{Conclusion and Outlook}

DPP is a multidisciplinary research project which explores the benefits of state-of-the-art geocommunication technologies to historical research. The focus of the cartographic efforts of the project lies on inherent cartographic issues, which are until now hardly considered in similar projects.

DPP uses high quality base maps, which are created specifically for this project, with additional layers relevant for the research questions. Story maps and database query functions allow researchers as well as the interested public to browse the data and explore the spatial relations of the entities of the case studies as well as to see the results of the research. The uncertainty of the various entities is also modelled in the database and will be represented in the map view.

However, these issues also represent challenges when building a complex system with various possible interactive elements. The uncertainty of the data is very inhomogeneous. Therefore, concepts to represent the uncertainty in all its aspects in various scales are explored.

Furthermore, when designing such a system, usability has to be considered. The aim is to create a flexible system, where the user can conduct her or his own queries and combination of layers. However, it should also be easy to use for non-GIS experts.

As of February 2017, the application is currently in its prototype stage, offering basic functionality. While the database structure is already mapped in the application, uncertainty representation is not yet implemented. Besides implementing advanced functionality, the uncertainty representation is the focus of the remainder of the project. The project and the software developed within are designed with possible extensions in mind, providing a basic framework for similar projects.

\section{References}

Bodenhamer J., Corrigan J., Harris T. M. (eds.) (2010) The Spatial Humanities: GIS and the Future of Humanities Scholarship. Bloomington and Indianapolis.

Eichert S. (2012) Frühmittelalterliche Strukturen im Ostalpenraum. Studien zu Geschichte und Archäologie Karantaniens. In: Forschung und Kunst 39, Klagenfurt.

Gregory I. N. \& Ell P. S. (eds.) (2007. Historical GIS. Technologies, Methodologies and Scholarship. New York.

Jänicke S. and Wrisley D. J. (2013) Visualizing Uncertainty: How to Use the Fuzzy Data of 550 Medieval Texts? in Proceedings of the Digital Humanities 2013.
Kriz K. (2013) Maps and Design - Influence of Depiction, Space and Aesthetics on Geocommunication. In: Kriz K, Cartwright W, Kin- berger M (Eds.), Understanding Different Geographies. Berlin, 9-24

Le Boeuf P., Doerr M., Ore C. E., Stead S. eds. (2013) Definition of the CIDOC Conceptual Reference Model. ICOM/CIDOC CRM Special Interest Group. http://www.cidoc-

crm.org/sites/default/files/cidoc_crm_version_6.2.1.pdf, accessed 23/02/2017.

MacEachren A. et al. (2005) Visualizing Geospatial Information Uncertainty: What We Know and What We Need to Know. in Cartog- raphy and Geographic Information Science, Vol 32, No. 3, pp. 139-160.

Popović M. (2014). Vlachen in der historischen Landschaft Mazedonien im Spätmittelalter und in der Frühen Neuzeit. In: Romanen und ihre Fremdbezeichnungen im Mittelalter: Walchen, Vlachen, Waliser [in press]

Popović M. (2015) Das Kloster Hilandar und seine Weidewirtschaft in der historischen Landschaft Mazedonien im 14. Jahrhundert. In: ПЕPIBO $\Lambda \mathrm{O} \Sigma-$ Mélanges offerts à Mme Mirjana Živojinović, Tome I. Belgrade 2015, 215-225.

Preiser-Kapeller J. (2010) erdumn, ucht, carayut'iwn. Armenian Aristocrats as Diplomatic Partners of Eastern Roman Emperors, 387- 884/885 AD. Armenian Review 52 (2010) 139-215

Preiser-Kapeller J. (2012) Networks of Border Zones Multiplex Relations of Power, Reli-gion and Economy in South-Eastern Europe, 1250-1453 CE. In: Proceedings of the 39th Annual Conference of Computer Applications and Quantitative Methods in Archaeolo-gy, "Revive the Past". Amsterdam, 381-393

Reuschel A. and Hurni L., (2011) Mapping Literature: Visualisation of Spatial Uncertainty in Fiction. in The Cartographic Journal, Vol. 48, No. 4, pp. 293-308.

Winckler K. (2012) Die Alpen im Frühmittelalter. Die Geschichte eines Raumes in den Jahren 500 bis 800 . Wien. 